\title{
Laparoscopic Treatment of Celiac Axis Compression Syndrome-Dunbar Syndrome
}

\author{
Marina GE, Luis RMN, Gabriel M, Marília F and Vladimir S*
}

Department of General, Gastric and Minimally Invasive Surgery, Brazil

ISSN: 2578-0379

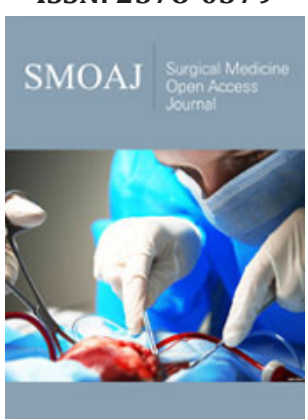

*Corresponding author: Vladimir S, Department of General, Gastric and Minimally Invasive Surgery, Brazil

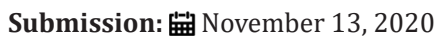

Published: 幽December 22, 2020

Volume 4 - Issue 2

How to cite this article: Marina GE, Luis RMN, Gabriel M, Marília F, Vladimir S. Laparoscopic Treatment of Celiac Axis Compression SyndromeDunbar Syndrome. Surg Med Open Acc J. 4(2). SMOAJ.000581. 2020 DOI: $10.31031 /$ SMOAJ.2020.04.000581

Copyright@ Vladimir S, This article is distributed under the terms of the Creative Commons Attribution 4.0 International License, which permits unrestricted use and redistribution provided that the original author and source are credited.

\section{Introduction}

Dunbar syndrome or celiac artery compression syndrome was described for the first time by Harjola in 1963. It's an infrequent clinical condition, with few criteria for diagnosis and with obscure pathophysiology. It is usually associated with an extrinsic compression upon the celiac axis near its takeoff from the aorta by fibrous diaphragmatic bands or sympathetic neural fibers. This syndrome is as uncommon cause for upper abdominal angina. The classic sympthoms include vomiting associated to pos prandial pain, weight loss and soufle in the epigastric region. Diagnosis is made by abdominal angiotomography, arteriography and magnetic resonance imaging. Surgical ligament release is indicated in case of severe compression of the celiac trunk or in patient's refractory to clinical treatment [1].

\section{Objective}

To present the case of a patient with Dunbar syndrome submitted to an arched ligament release by laparoscopy.

\section{Case Report}

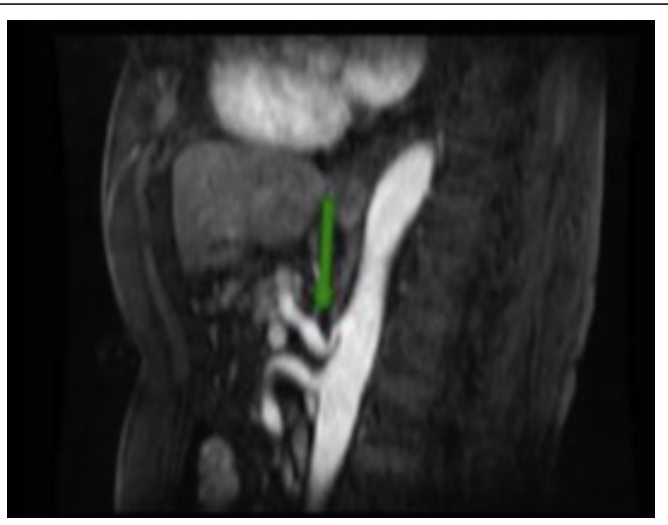

Figure 1: Median arcuate ligament crossing anterior to the celiac artery.

Female patient, 74 years old, vomiting with abdominal postprandial pain refractory to clinical treatment. At examination, her abdomen was a distended, sore to palpation on epigastric region. She was submitted to an upper digestive endoscopy with no changes [2]. The patient was then submitted to a MRI with showed a pronounced stenosis of the celiac trunk, due to compression by the arcuate ligament of the diaphragm (Figure 1). The patient was submitted to laparoscopic surgery. Intraoperatively, the clear extrinsic nature of compression of the celiac trunk by the diaphragmatic structures was well assessed visually and compressing pathologic muscular fibers were divided (Figure 2); the ligament was excised with resection of the neural and fibrotic tissues surrounding the aortic and visceral vessels. 
Patient improved with no intercurrence and was discharged on the second postoperative day.

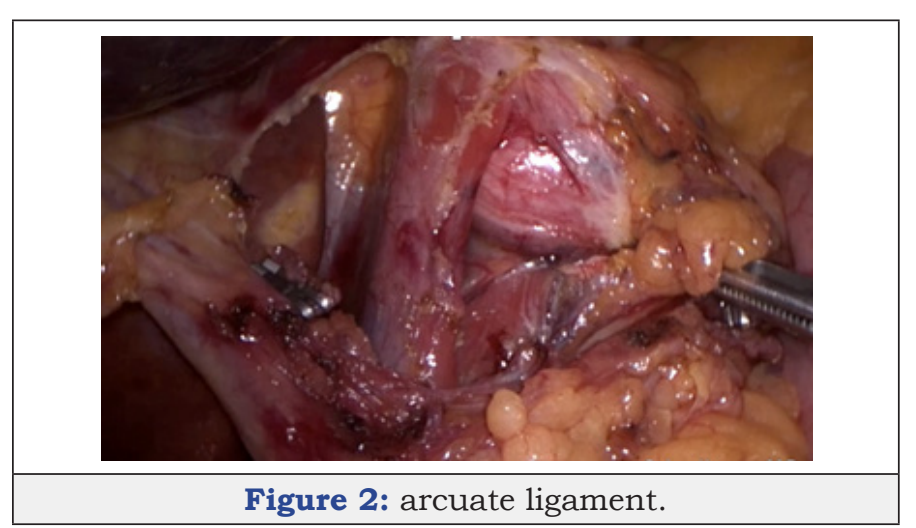

\section{Conclusion}

Laparoscopic treatment of celiac axis compression syndrome is technically feasible and a useful alternative, in centers with experience in major laparoscopic surgery [3]. Surgical treatment should be considered for patients with severe stenosis of the celiac trunk and with symptomatology refractory to clinical treatment.

\section{References}

1. Torres OJ, Gama FOP, Torres CC, Medeiros RM, Oliveira CMB, et al. (2017) Laparoscopic treatment of dunbar syndrome: A case report. Int J Surg Case Rep 37: 230-232.

2. Nguyen T, Neale M, Lane R, Schiavone V, Samra JS, et al. (2012) Laparoscopic management of the median arcuate ligament syndrome. ANZ J Surg 82(4): 265-268.

3. Akkapulu N, Kilic Y, Aydın H, Aran O (2013) Dunbar's syndrome: A rare and unclear entity. Turk J Gastroenterol 24(3): 450-451.

For possible submissions Click below: 